\title{
Comparison of Two Different Sprint Interval Training Work-to-Rest Ratios on Acute Inflammatory Responses
}

\author{
Christopher R. Harnish ${ }^{* *}$ and Roy T. Sabo ${ }^{2}$
}

\begin{abstract}
Background: The study aims to compare how work-to-rest ratio $(W: R)$ influences insulin sensitivity $\left(S_{i}\right)$ and inflammatory responses following one session of sprint interval training (SIT).

Methods: Thirteen men and two women completed a cross-over comparison of two SIT interventions-Tabata (TAB), $10 \times 20$-s sprints/10-s rest, and Wingate $(\mathrm{WIN}), 5 \times 30$-s sprints with 270-s rest. IL-6, IL-10, and TNF-a were assessed at baseline, immediately following, and $1 \mathrm{~h}$ after SIT, as well as prior to the 24-h post-exercise oral glucose tolerance tests (OGTTs).

Results: Participants were $23.8( \pm 3.5)$ years old and $180.0( \pm 10.2) \mathrm{cm}$ tall, weighed $78.5(13.0) \mathrm{kg}$, and had $16.9( \pm 6.5)$ $\%$ body fat, with a mean $\mathrm{VO}_{2 \text { peak }}$ of $42.0( \pm 7.9) \mathrm{ml} \mathrm{kg}^{-1} \mathrm{~min}^{-1}$. There were no differences in total work $(\mathrm{kJ})$ between TAB $(64.7 \pm 12.0)$ and WIN $(68.0 \pm 15.0)$. Mean $( \pm 95 \% \mathrm{Cl}) \mathrm{S}_{\mathrm{i}} 24 \mathrm{~h}$ changed $-2.8(-5.1,-0.5)$ from baseline after TAB and $-3.9(-6.9,-0.9)$ after WIN. Cytokines were measured in $\mathrm{pg} \mathrm{ml}^{-1}$ and expressed as mean change $( \pm 95 \% \mathrm{Cl})$. IL-6 increased significantly immediately following SIT for TAB $0.70(0.23,1.17)$, and WIN $1.11(0.60,1.62)$, and remained elevated $1 \mathrm{~h}$ post SIT for TAB $1.10(0.37,1.83)$, and WIN $0.95(0.26,1.65)$. IL-10 showed a significant positive change immediately following exercise for TAB $1.53(0.77,2.29)$ and WIN $1.59(0.58,2.59)$. TNF-a also increased immediately both TAB $3.26(1.57,4.96)$ and WIN $3.05(0.56,5.54)$ and was directly proportional to IL-10 $(r=0.64, p<0.0001)$.

Conclusions: W:R did not alter either the inflammatory or metabolic response following SIT nor does SIT improve 24-h $\mathrm{S}_{\mathrm{i}}$, despite increased levels of IL-10.
\end{abstract}

Keywords: SIT, Cytokines, Myokines, Wingate, Tabata

\section{Key Points}

- Work-to-rest ratio does not significantly alter the inflammatory or metabolic responses of sprint interval training (SIT).

- An acute bout of SIT does not improve insulin sensitivity in non-obese persons.

- Transient increases in anti-inflammatory cytokines, like IL-6 and IL-10, are associated with insulin sensitivity following SIT.

- There appears to be a strong positive relationship between IL-10 and TNF- $\alpha$ following SIT.

\footnotetext{
* Correspondence: charnish@ferrum.edu

${ }^{1}$ Department of Health and Human Performance, Ferrum College, Ferrum, VA 24088, USA

Full list of author information is available at the end of the article
}

\section{Background}

High-intensity interval training, including sprint interval training (SIT), has been proposed as an effective means for improving both exercise performance and metabolic function $[2,4,5,9,13,14,18,33,37,39]$. While it has been shown that repeated sessions of SIT using long rest periods (i.e., low work-to-rest ratio) elicit improvements in endurance performance [4, 33 ] and $S_{i}[2,37,39]$, a single bout of SIT appears ineffective for improving $S_{i}[3,30,38]$. In contrast, Whyte et al. [37] showed that a single maximal effort of matched work could improve $S_{\mathrm{i}}$, indicating that the mechanisms for metabolic improvements following a single bout of high-intensity exercise require further investigation. 
There are many possible mediators of $\mathrm{S}_{\mathrm{i}}$ and glucose uptake following exercise, including cytokines $[10,11,26-28,31]$. It is also important to note that while some describe exercise-induced IL-6 release as anti-inflammatory [26], others continue to view IL-6 as pro-inflammatory [22-24], complicating the interpretation of their impact. For example, endurance exercise has long been viewed as anti-inflammatory, resulting in significant increases in circulating cytokines like IL-6 and IL-10, which are believed to improve glucose uptake [21, 26]. In contrast, SIT is viewed as pro-inflammatory with significant increases in IL-6 within $1 \mathrm{~h}$ after training [22-24]. More recently, however, Lira et al. [19] have shown that both upper and lower extremity Wingate sprints elicit similar significant increases in IL-10, but not IL-6 immediately following exercise, indicating that high-intensity sprint training may have an anti-inflammatory effect immediately following exercise. Furthermore, unlike endurance exercise, which improves $S_{i}$ after just a single bout, SIT has only been shown to improve $S_{i}$ after two or more weeks of training. Therefore, it is unclear whether inflammatory cytokines are influencing the metabolic changes following a single bout of exercise.

Another important, yet unstudied area, is the effect of work-to-rest ratio (W:R) on the inflammation or $\mathrm{S}_{\mathrm{i}}$. W:R is an important mediator of metabolic, cardiovascular, and endocrine responses during and after interval and resistance training $[8,15,16]$, but data are scarce as to how it influences exercise inflammatory response. Available evidence suggests that a brief bout of maximal sprints with very short rest periods could elicit a significant increase in both IL-6 and IL-10 [11, 25], as well as provide an exercise stimulus more akin to the brief time trial used by Whyte et al. [37]. Thus, we could elucidate whether any single bout of SIT could improve $S_{\mathrm{i}}$, and whether inflammatory cytokines are related to such an improvement.

The purpose of this study was to compare the impact of W:R on $S_{\mathrm{i}}$ and inflammatory indices. We hypothesized that when matched for total work (kJ), SIT using brief rest periods (W:R $=2: 1$ ) would improve $S_{i}$ and associated inflammatory markers more than SIT using long rests $(W: R=1: 9)$.

\section{Methods}

\section{Participants}

A total of 13 men and 2 women were actively recruited for the study. All participants were evaluated for safe exercise participation using an American College of Sports Medicine (ACSM) risk factor assessment and informed of the purposes of the study before signing an informed consent document approved by the Virginia Commonwealth University (VCU) Institutional Review Board. Inclusion criteria included men and women between the ages of 1835 years old who were minimally active-at or below $3 \times 30 \mathrm{~min}$ of activity/week, and had a body fat $\leq 25 \%$ for men and $32 \%$ for women. Exclusion criteria were any person exceeding the body fat cut off, orthopedic limitations preventing full participation in the study, prediabetes or diabetes mellitus, reported hypothyroidism, renal disease, and/or anyone considered high risk for exercise participation based on current ACSM clinical guidelines.

\section{Experimental Protocol}

All experimental procedures were performed in accordance with the ethical standards of the Declaration of Helsinki and approved by the VCU Institutional Review Board. The design (Fig. 1) was similar to previous SIT studies and consisted of a 1-week intra-subject control period. During this period, participants performed baseline (B) and pre-training (PRE) oral glucose tolerance tests (OGTTs). Participants then completed two different acute SIT protocols-Tabata and Wingate, utilizing a counter balanced cross-over trial design, with each training bout separated by no less than 1 week. Subject 1 was randomly assigned to either Tabata or Wingate first, completing the other session second; each subsequent subject was then assigned to the opposite group first. All exercise took place using a mechanically braked Monark Peak Bike (Monark Exercise AB, Sweden) equipped with an SRM power meter (SRM Service Center, Inc., Colorado Springs, CO). Blood samples ( 10 ml) were taken immediately following, and $1 \mathrm{~h}$ after each training session, as well as $24 \mathrm{~h}$ after exercise; this corresponded to the initial resting sample prior to the postexercise OGTT. Women participants were tested during the follicular phase of their self-reported menstrual cycle to minimize the impact on cytokine levels.

\section{Dietary Control}

Each subject was asked to complete a 3-day dietary recall form prior to completing any blood analysis. Dietary analysis was performed by a registered dietician for later comparison, and participants were asked to pick 1 day within the recall and repeat those meals the day before each OGTT, recording the meals for those days. Additionally, each participant completed all training sessions after a 12-h fast, including alcohol and caffeine, and they abstained from significant activity $24 \mathrm{~h}$ prior to all exercise sessions and OGTTs. 


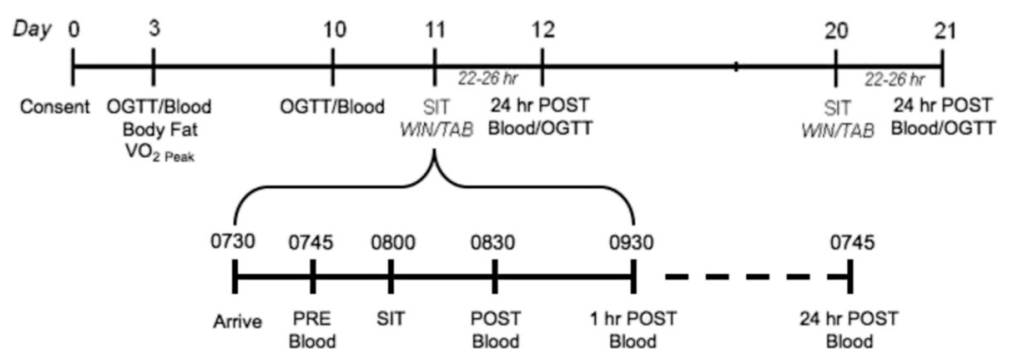

Fig. 1 Graphic summary of the experimental design for the study. OGTT oral glucose tolerance test, SIT sprint interval training, TAB Tabata short recovery exercise, WIN Wingate long recovery exercise

\section{Preliminary Testing and Evaluation}

On the initial assessment day (day 3) and during the OGTT, participants completed body composition analysis using bioelectrical impedance analysis (RJL Quantum IV, RJL Systems, Inc., Clinton Township, MI), where participants lay supine for a period of 20 min to allow body fluids to equilibrate across the body. During this time, small electrodes were placed on the right ankle and wrist. Body composition was then estimated using web-based software (RJL Interactive Online BIA, RJL Systems Inc., Clinton Township, MI). Following the initial OGTT, physiologic testing included bicycle $\mathrm{VO}_{2 \text { Peak }}$ testing. Testing was completed on the SRM equipped Monark bike; power (W) was measured for each stage. $\mathrm{VO}_{2}$ and $\mathrm{HR}$ were measured continuously using a Parvo OneMax system (Parvo Medics, Salt Lake City, UT) and Polar HR monitor (Polar Electro Inc., New Success, NY), respectively. Participants were instructed to pedal at their preferred cadence throughout testing. The initial workload was set at 1.5 KP with an approximate work rate of $100 \mathrm{~W}$, increasing by $0.5 \mathrm{KP}$ every 2 min until volitional exhaustion was reached, or the subject could not maintain their chosen cadence. Peak power output at $\mathrm{VO}_{2 \text { Peak }}$ was calculated as the highest average 1-min power output achieved during the final stage of testing; this power output was termed Power at $\mathrm{VO}_{2 \text { Peak }}$.

\section{Exercise Protocols}

All SIT sessions began between 0700 and 0900, and each subject's sessions took place at the same time of the morning. All sprint bouts began with a 10-min unloaded warm-up at $\sim 70 \mathrm{rpm}$. Participants then pedaled against a resistance equivalent to $7 \%$ $\left(0.07 \mathrm{~kg} \mathrm{~kg}^{-1}\right)$ body mass for Wingate sprints and slightly lower $5 \%\left(0.05 \mathrm{~kg} \mathrm{~kg}^{-1}\right)$ body mass for Tabata. The former resistance has been shown to produce optimal power output and reliable measurement [12], while the latter was shown to be optimal during pilot data work prior to the study. Participants were instructed to pedal as fast as possible for $\sim 2 \mathrm{~s}$ before the load is applied and to continue to crank while being provided with vigorous verbal encouragement throughout each sprint. The Wingate protocol consisted of a total of five 30-s sprints with approximately 4-min recovery (i.e., very slow unloaded pedaling), while those completing the Tabata protocol consisted of ten 20-s sprints with 10-s recovery. The number of intervals performed for each protocol was chosen based on pilot data indicating a close match in total work $(\mathrm{kJ})$.

Peak and mean power (W), as well as total work, were measured and stored using the SRM power meter and downloaded for later analysis using commercially available software (Training Peaks 3.0, Training Peaks, Boulder, CO). Blood lactate samples $(5 \mu \mathrm{l})$ were measured from the fingertip using a small plastic lancet prior to exercise, immediately following, 1 and $3 \mathrm{~min}$ after exercise, and analyzed using a Lactate Scout Analyzer (EKF diagnostic sales $\mathrm{GmbH}$, Barleben/Magdeburg). Each sprint session lasted between 15 and $30 \mathrm{~min}$ with warm-up. For descriptive purposes, the relative average power output during each SIT session was expressed a \% Power at $V \mathrm{O}_{2 \text { Peak }}$.

\section{Blood Analysis}

Hemoglobin concentration $\left(\mathrm{g} \mathrm{dL}^{-1}\right)$ and hematocrit (\%), using the micro-hematocrit method, were measured in duplicate and then used to estimate percentage changes in PV [6]. An indwelling venous catheter was inserted to allow for convenient blood draws. Blood samples $(\sim 10 \mathrm{ml})$ were collected together using gray top sodium fluoride tubes (OGTT) and gold top serum-separator tubes (cytokines) throughout testing and then centrifuged after each session at $4000 \mathrm{rpm}$ for $15 \mathrm{~min}$ at $4{ }^{\circ} \mathrm{C}$. Separated plasma was immediately removed and stored in capped $1.5-\mathrm{ml}$ polypropylene tubes frozen at $-80{ }^{\circ} \mathrm{C}$ until later analysis. 
Table 1 Comparison of Tabata and Wingate protocols and exercise session data

\begin{tabular}{llll}
\hline & Tabata & Wingate & $p$ value \\
\hline Mean power $(\mathrm{W})$ & $223.2(40.9)^{\mathrm{a}}$ & $457.8(84.1)^{\mathrm{a}}$ & $<0.0001$ \\
\% Power at $\mathrm{VO}_{2 \text { Peak }}$ & $95.6(8.9)^{\mathrm{a}}$ & $196.8(24.4)^{\mathrm{a}}$ & $<0.0001$ \\
Work (kJ) & $64.7(12.0)$ & $68.0(15.0)$ & 0.515 \\
BLC (mM) & $12.8(2.6)$ & $12.6(2.6)$ & 0.831 \\
HR (bpm) & $180.7(9.5)$ & $173.9(9.0)^{\mathrm{a}}$ & 0.0272 \\
\hline
\end{tabular}

Data are presented as means $( \pm \mathrm{SD})$

${ }^{\mathrm{a}}$ Significant $(p<0.05)$ difference between interventions

\section{Oral Glucose Tolerance Tests}

OGTTs were completed following insertion of a catheter. Blood ( $\sim 10 \mathrm{ml})$ was drawn before, as well as 30, 60, 90, and $120 \mathrm{~min}$ after ingestion of a $75 \%$ Glucola drink (Fisher Science Inc., Philadelphia, PA). Plasma glucose concentrations $\left(\mathrm{mg} \mathrm{dl}^{-1}\right)$ were measured using the autoanalyzer glucose oxidase method, while plasma insulin concentrations $\left(\mathrm{mU} \mathrm{l}^{-1}\right)$ were determined by ELISA (R\&D Systems, Inc, Minneapolis, MN). The coefficient of variation $(\mathrm{CV})$ for baseline Cederholm $\mathrm{S}_{\mathrm{i}}$ was $4.8 \%$.

\section{Inflammatory Markers}

Inflammatory markers of interest included IL-6 (IL-6 B), IL-10 (IL-10 B), and TNF- $\alpha$ (TNF- $\alpha$ B) measured during baseline testing periods, as well as following each bout of SIT based on the time periods reported in prior research [22-24]. At baseline, samples were analyzed from the blood taken at minute 0 . On SIT days, $10 \mathrm{ml}$ of blood was taken prior to, immediately following exercise $(\mathrm{P})$, and $1 \mathrm{~h}$ later (P 1). A final cytokine measurement was taken prior to the OGTT $\sim 24 \mathrm{~h}$ after the SIT bout (P 24). Plasma concentrations of IL- 6, IL-10, and TNF- $\alpha$ were determined using interleukin-specific Humakine ELISA kits (R\&D Systems, Minneapolis, $\mathrm{MN}$ ), each completed according to manufacturer's instructions. Coefficients of variation (CV) for IL-6, IL-10, and TNF- $\alpha$ were 9.9, 6.1, and $6.6 \%$, respectively.

\section{Statistical Analysis}

Data analysis was performed using commercially available software (Jump 13.0, SAS Institute Inc, Cary, NC). During the design process, power analyses run for cytokines and $\mathrm{S}_{\mathrm{i}}$ estimated that an $N$ of 15 provides a power of 0.85 . All data are presented as means $\pm \mathrm{SD}$. Area under the curve (AUC) was calculated using the trapezoidal rule, while the Cederholm index, which represents peripheral $\mathrm{S}_{\mathrm{i}}$, was calculated using the formula:
BW is the body weight, $G_{0}$ and $G_{120}$ are plasma glucose concentration at 0 and $120 \mathrm{~min}\left(\mathrm{mmol} \mathrm{l}^{-1}\right)$, and $I_{\text {mean }}$ and $G_{\text {mean }}$ are the mean insulin $\left(\mathrm{mU} \mathrm{l}^{-1}\right)$ and glucose $\left(\mathrm{mmol} \mathrm{l}^{-1}\right)$ concentrations during the OGTT.

All exercise responses $\left(S_{i}\right.$, glucose AUC, insulin AUC, and cytokines) are reported as absolute values and changes from baseline. Data were analyzed using absolute change responses from baseline $\pm 95 \%$ confidence intervals; 95 \% CI changes that failed to cross 0 (i.e., 0 change) were considered significant. Dependent $t$ tests were run to compare change in $\mathrm{S}_{\mathrm{i}}$ following Tabata and Wingate SIT from baseline and at $24 \mathrm{~h}$. IL-6, IL-10, and TNF- $\alpha$ were compared between SIT groups using a similar repeated measures ANOVA model, though with a four-level time indicator (baseline, post, 1 h, 24 h). Finally, Pearson's correlation coefficients were calculated to examine the relationships between $S_{i}$ and changes in cytokine response.

\section{Results}

Fifteen participants completed both sprint sessions, with one subject unable to complete a 24-h follow-up after the Wingate session due to inclement weather. Participants were $23.8( \pm 3.5)$ years old and $180.0( \pm 10.2) \mathrm{cm}$ tall, weighed $78.5(13.0) \mathrm{kg}$, and had $16.9( \pm 6.5) \%$ body fat, with a mean $\mathrm{VO}_{2 \text { Peak }}$ of $42.0( \pm 7.9) \mathrm{ml} \mathrm{kg}^{-1} \mathrm{~min}^{-1}$ at 237.0 $( \pm 56.6)$ W. Dietary analysis indicated our participants consumed a diet consisting of $2077.5 \pm 132.3 \mathrm{kcal}$ from $81.9 \pm$ $8.0 \mathrm{~g}$ of fat, $243.2 \pm 14.4 \mathrm{~g}$ of carbohydrate, and $93.2 \pm 6.8 \mathrm{~g}$ of protein, and were without any remarkable findings. Table 1 provides a summary comparison of SIT session variables. The \% Power at $\mathrm{VO}_{2 \text { Peak, }}$ was significantly higher $(p<0.0001)$ during WIN $(196.8 \pm 24.4 \%)$ compared to TAB $(95.6 \pm 8.9 \%)$. While there were no differences in total $\mathrm{kJ}(p=0.5152)$ or blood lactate $(p=0.8307)$ between SIT sessions, HR was significantly lower ( $p=$ 0.0272) during Wingate sessions. Figure 2 depicts sample SIT sessions for one subject. Overall responses for men and women overlapped and trended similarly and therefore were analyzed together.

\section{Insulin Sensitivity}

Baseline $\mathrm{S}_{\mathrm{i}}$ for all participants was $75.9( \pm 1.0) \mathrm{mg} I^{2}$ $\mathrm{mM}^{-1} \mathrm{mU}^{-1} \mathrm{~min}^{-1}$. Table 2 summarizes the $\mathrm{S}_{\mathrm{i}}$, glucose AUC, and insulin AUC data for both SIT sessions using an intent-to-treat analysis. As noted above, one subject was unable to complete a 24-h post testing, including OGTT, after WIN training. The data indicate that $\mathrm{S}_{\mathrm{i}}$ was significantly depressed after both TAB, $-2.8(-5.1,-0.5)$,

$$
\underline{\text { Cederholm } S_{\mathrm{i}}=75,000+\left(G_{0}-G_{120}\right) \times 1.15 \times 180 \times 0.19 \times \mathrm{BW} / 120 \times G_{\text {mean }} \times \log \left(I_{\text {mean }}\right)}
$$




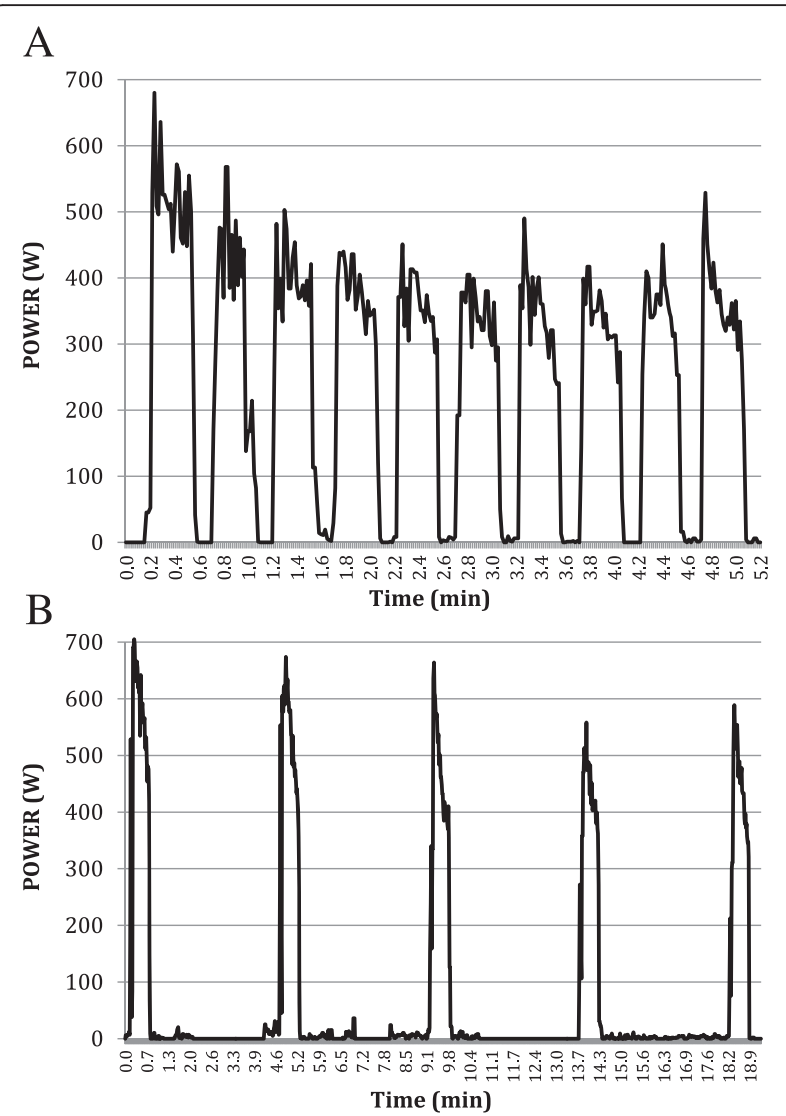

Fig. 2 Sample sprint interval training session of one participant for Tabata (a) and Wingate (b)

and WIN, $-3.9(-6.9,-0.9)$, but no differences between sprint interventions $(p=0.6723)$, and AUC for neither glucose nor insulin were significantly impacted (see Table 2).

\section{Inflammatory Cytokine Response}

Changes in glucose, insulin, and cytokines are summarized in Table 2. Plasma cytokine levels for IL-6, IL-10, and TNF- $\alpha$ were measured in all 15 participants during preOGTT (baseline) and TAB test sessions, where 14 participants of 15 participants were measured $24 \mathrm{~h}$ after WIN. IL-6 increased significantly immediately following SIT for TAB 0.70 (0.23, 1.17), and WIN $1.11(0.60,1.62)$, and remained elevated 1 -h post SIT for TAB $1.10(0.37,1.83)$, and WIN $0.95(0.26,1.65)$. IL-10 showed a significant positive change immediately following exercise for TAB $1.53(0.77,2.29)$ and WIN $1.59(0.58,2.59)$. TNF- $\alpha$ also increased immediately both TAB $3.26(1.57,4.96)$ and WIN $3.05(0.56,5.54)$. All cytokines returned to baseline levels $24 \mathrm{~h}$ after exercise. The relative anti-inflammatory response, expressed as a ratio between IL-10 and TNF- $\alpha$ did not change significantly for any time period $(p=1.0)$ and ranged from 0.62 to a peak of 0.88 and 0.79 immediately following $\mathrm{TAB}$ and WIN, respectively. Results of all significant Pearson correlations are summarized in Table 3. IL- 6 was not related to either IL-10 or TNF- $\alpha$ but showed a strong inverse relationship at baseline with $\mathrm{S}_{\mathrm{i}}$. IL-10 and TNF- $\alpha$ were positively related $(r=0.64, p<0.001)$ overall, as well as immediately following SIT.

\section{Discussion}

The purpose of this study was to compare how W:R influences inflammatory and metabolic responses following a single bout of SIT. It was believed that when matched for total work $(\mathrm{kJ})$, SIT using brief rest periods $\left(\mathrm{W}: \mathrm{R}=2: 1\right.$ ) would elicit a greater improvement in $\mathrm{S}_{\mathrm{i}}$ proportional to a higher cytokine response than SIT using long rests $(\mathrm{W}: \mathrm{R}=1: 9)$. However, our data indicate that both SIT sessions depressed $\mathrm{S}_{\mathrm{i}} 24 \mathrm{~h}$ after exercise. In contrast, both sessions increased IL-6, IL-10, and TNF- $\alpha$ for up to $1 \mathrm{~h}$ after exercise. While IL-10 and TNF- $\alpha$ release appear to be directly proportional to each other following SIT, their impact on $\mathrm{S}_{\mathrm{i}}$ is unclear.

\section{SIT and $S_{i}$}

A major finding of this research was that neither TAB nor WIN SIT improved $S_{i}$ P 24, indicating that W:R does not influence $S_{i}$ in healthy young adults. In the present study, $S_{i}$ was actually significantly decreased by $5 \%$ following WIN, while 5 min of TAB decreased $S_{i}$, by $3.6 \% 24 \mathrm{~h}$ after exercise. This finding was consistent among participants in both SIT trials, with only 3 of 15 participants actually improving $S_{i}$ following TAB. Close examination of these data show that 2 of 15 participants had $15 \%$ or greater decrease in $\mathrm{S}_{\mathrm{i}}$ following WIN. Interestingly, the (male) subject with the largest decrease in $\mathrm{S}_{\mathrm{i}}, \sim 15 \%$ following TAB and $20 \%$ following WIN, also had the highest body fat at $24.8 \%$. However, no other differences, including diet, were noted between participants, and removal of these outliers did not reverse the trend toward reduced $\mathrm{S}_{\mathrm{i}}$.

The lack of improvement following TAB was unexpected because total work was similar to that of the extended sprint reported by Whyte et al. [38]. In that study, subjects performed two interventions, four WIN intervals, and a maximal $\sim 200$-s extended sprint (ES), both resulting in $\sim 62 \mathrm{~kJ} . \mathrm{S}_{\mathrm{i}}$ improved significantly $24 \mathrm{~h}$ after the ES, but not WIN. In fact, a single bout of WIN has failed to improve $S_{i}$ in other studies as well $[3,30]$. These researchers suggested that the key factor for acute improvements in $S_{i}$ may be ATP turnover [36], which would be maximal during the 200 -s continuous time trial used in their study. It was this premise that influenced our choice of the Tabata SIT intervention.

As reported by Tabata et al. [34, 35], 4 min of the 20-s work to 10 -s rest ratio maximally stimulated oxygen consumption and anaerobic capacity; peak $\mathrm{VO}_{2}$ in the final $10 \mathrm{~s}$ of the 4-min Tabata was similar to their 
Table 2 Comparison of baseline (mean \pm SD) and mean $( \pm 95 \% \mathrm{Cl})$ changes for glucose, insulin, and cytokine measures

\begin{tabular}{|c|c|c|c|c|}
\hline \multirow[t]{2}{*}{ Measure } & \multirow[b]{2}{*}{ Baseline } & \multirow{2}{*}{$\begin{array}{l}\text { Change } \\
\text { Tabata }\end{array}$} & \multirow{2}{*}{$\begin{array}{l}\text { Change } \\
\text { Wingate }\end{array}$} & \multirow[t]{2}{*}{ Group comparison } \\
\hline & & & & \\
\hline Insulin sensitivity & 75.9 (3.2) & $-2.8(-5.1,-0.5)^{\mathrm{a}}$ & $-3.9(-6.9,-0.9)^{\mathrm{a}}$ & 0.5115 \\
\hline Glucose AUC & $444.1(78.9)$ & $-17.8(-12.90,48.4)$ & $-14.8(-35.6,27.8)$ & 0.3228 \\
\hline Insulin AUC & $91.9(55.2)$ & $-12.4(-6.5,31.2)$ & $-4.7(-17.45,19.0)$ & 0.3494 \\
\hline \multicolumn{5}{|l|}{ Cytokine response } \\
\hline $\mathrm{IL}^{-6}\left(\mathrm{pg} \mathrm{m} \mathrm{l}^{-1}\right)$ & $0.85(0.48)$ & & & \\
\hline Post 0 & & $0.70(0.23,1.17)^{\mathrm{b}}$ & $1.11(0.60,1.62)^{b}$ & 0.9091 \\
\hline Post $1 \mathrm{~h}$ & & $1.10(0.37,1.83)^{b}$ & $0.95(0.26,1.65)^{b}$ & 0.9991 \\
\hline Post $24 \mathrm{~h}$ & & $-0.13(-0.38,0.13)$ & $0.47(-0.34,1.28)$ & 0.6706 \\
\hline $\mid \mathrm{L}-10\left(\mathrm{pg} \mathrm{ml^{-1 }}\right)$ & $3.69(1.46)$ & & & \\
\hline Post 0 & & $1.53(0.77,2.29)^{b}$ & $1.59(0.58,2.59)^{b}$ & 1.0000 \\
\hline Post $1 \mathrm{~h}$ & & $-0.4091(-2.050,1.23)$ & $0.31(-0.56,1.18)$ & 0.8771 \\
\hline Post $24 \mathrm{~h}$ & & $-0.56(-1.37,0.23)$ & $-0.03(-0.79,0.73)$ & 0.9538 \\
\hline TNF-a $\left(p g \mathrm{ml}^{-1}\right)$ & $3.96(3.45)$ & & & \\
\hline Post 0 & & $3.26(1.57,4.96)$ & $3.05(0.56,5.54)$ & 1.0000 \\
\hline Post $1 \mathrm{~h}$ & & $-1.41(-3.93,1.11)$ & $-0.94(-3.22,1.35)$ & 0.9993 \\
\hline Post $24 \mathrm{~h}$ & & $-0.59(-2.72,1.53)$ & $0.08(-2.03,2.20)$ & 0.9973 \\
\hline
\end{tabular}

Group comparison $p$ values indicate there were no differences between sprint groups

${ }^{a} 95 \% \mathrm{Cl}$ changes that failed to cross 0 (i.e., 0 change) were considered significant with a significant decrease above baseline

b $95 \% \mathrm{Cl}$ changes that failed to cross 0 (i.e., 0 change) were considered significant with a significant increase above baseline

participants' $\mathrm{VO}_{2 \max }$, as was the accumulated $\mathrm{O}_{2}$ deficit. In order to match work in our study, our TAB SIT session lasted an additional $50 \mathrm{~s}$ (i.e., two 20-s sprints), with a total duration exceeding Whyte's ES but likely maximally stimulating mitochondrial ATP production. Therefore, work and ATP turnover may not be critical factors at play. Of particular note, however, Whyte et al. [38] enrolled overweight and obese male participants, while we studied healthy young adults, who were relatively lean (body fat $\%=16.9$ ). Not surprisingly, the outlier showing the greatest drop in $\mathrm{S}_{\mathrm{i}}$ following $\mathrm{TAB}$ also had the highest body fat at nearly $25 \%$. Therefore, overweight and obese individuals may be more responsive to single bouts of SIT than lean individuals. Changes in $S_{i}$

Table 3 Summary of significant Pearson correlation coefficients

\begin{tabular}{llll}
\hline Independent variable & Dependent variable & $r$ & $p$ value \\
\hline Baseline IL-6 & Baseline $\mathrm{S}_{\mathrm{i}}$ & $r=-0.65$ & \\
TNF-a & IL-10 & $r=0.64$ & $<0.0001$ \\
Tabata & & & \\
$\quad$ TNF-a P & IL-10 & $r=0.83$ & 0.0027 \\
$\quad$ TNF-a P 24 & IL-10 & $r=0.76$ & 0.0472 \\
Wingate & & & \\
$\quad$ TNF-a P & IL-10 & $r=0.93$ & 0.0001 \\
\hline
\end{tabular}

No other significant relationships were observed

$B$ baseline, $P$ immediately post exercise, $P 2424 \mathrm{~h}$ post exercise following a single session of SIT are more complex and warrant further investigation.

\section{SIT Impact on the Inflammatory Response}

Another major finding of this study was that W:R does not alter the effect on inflammatory cytokine release following SIT, as there were no differences between SIT groups for any cytokine measured. In addition, we noted that IL-10 release was not dependent on IL- 6 but that increases in IL-10 immediately following SIT were directly proportional to TNF- $\alpha(r=0.64, p<0.001)$, supporting, in part, the findings of Lira et al. [19], but not other SIT research. For example, prior research by Meckel et al. [22, 23] and Nemet et al. [24] reported that running sprint exercise significantly increased IL-6 $1 \mathrm{~h}$ after exercise but did not influence IL-10 [24] in trained men and women. In contrast, Brestoff et al. [3] showed that a session of five Wingate sprints (1:9 W:R) did not alter IL- 6 or TNF- $\alpha$ release after exercise in recreationally active men and women. Most recently, however, Lira et al. [19] reported a similar significant increase in IL-10 immediately following lower extremity Wingate sprints, but not upper extremity sprints; they also failed to show an increase in TNF- $\alpha$.

A major premise of cytokine release following endurance exercise is that IL-6 is released directly from the muscle, making it a myokine [26], and that this release from the muscle influences its anti-inflammatory 
role $[27,28]$. Further, IL- 6 is believed to be a stimulant to IL-10 release, which is a known inhibitor of TNF- $\alpha[1,7,32]$. These data suggest that SIT, regardless of W:R, results in a nearly $60 \%$ increase in TNF- $\alpha$ immediately following exercise, as well as a similar increase in IL-10, which leads to a consistent yet insignificant increase in the IL-10-to-TNF- $\alpha$ ratio. This finding is important for two reasons. First, it supports recently published data indicating that IL-10 increases following intense exercise independent of IL-6. Second, it suggests that IL-10 may increase in response to TNF- $\alpha$. The latter is supported by our data showing that both IL-10 and TNF- $\alpha$ increased significantly immediately after both TAB and WIN, which is then followed by a significant decrease in TNF- $\alpha 1 \mathrm{~h}$ after exercise. Furthermore, IL-10 levels were strongly related $(r=0.87, p<0.005)$ to TNF- $\alpha$ immediately following both SIT sessions, which is not surprising, as IL-10 has been shown to be a potent mediator of TNF- $\alpha[1,7]$. A pro-inflammatory response, though transient, may be an important stimulus for long-term adaptation [5], similar to the role reactive oxygen species, like $\mathrm{H}_{2} \mathrm{O}_{2}$, and lactate accumulation, play in mitochondrial biogenesis $[17,20]$. It is also possible it simply reflects increased glycogenolysis and lipolysis [21].

\section{SIT: Inflammation and Glucose Regulation}

Presently, our understanding of cytokine release following SIT is limited, and any relationship to acute improvement in $S_{i}$ is largely based on endurance exercise studies [10, 26, 28, 32]. Our data indicate that SIT does not have an acute impact on IL-6 release, nor does acute SIT influence on $S_{i}$, regardless of W:R. Additionally, there was no relationship between cytokine release and $\mathrm{S}_{\mathrm{i}}$, suggesting that inflammatory cytokines do not play a significant role in the improved $S_{i}$ seen in SIT studies of at least 2 weeks [2, 30, 37, 39]. Newly published data indicate a disruption in the sarcoplasmic reticulum (SR) following a single bout of SIT [29]. The disruption in the SR has been postulated as the trigger for reported improvements in the chronic endurance performance and metabolic function following two or more weeks of SIT $[4,29]$. For example, Coffey and Hawley [5] outlined four distinct signals for mitochondrial biogenesis and improved glucose regulation, including mechanical stretch, increased intramuscular calcium concentration, reduced muscle ATP concentrations, and an increase in ROS, or other disruptions to muscle homeostasis. While Place et al. [29] reported the latter two signals in their recent work, only the last would support the role of inflammatory cytokines in this process. Nonetheless, far more work is needed before direct conclusions can be drawn.
These results add to a growing body of literature elucidating the inflammatory response following SIT and its possible role in the chronic training improvements reported from a variety of sprint protocols. While intriguing, our results represent a relatively healthy population of college-age adults. The fact that these data seem to contrast those of Meckel et al. [22, 23], who studied sprint training in elite athletes during run SIT, indicates that population characteristics, fitness level, and mode likely influence inflammation in SIT. The results in the present investigation demonstrate the need for examining a number of mechanisms in various populations to better understand the possible health benefits of SIT.

\section{Conclusions}

In conclusion, our data indicate that W:R does not significantly alter the metabolic and inflammatory responses following SIT of similar work. Moreover, it appears that despite rapid increases in IL-6 and IL-10, SIT actually suppressed $S_{i} 24 \mathrm{~h}$ after exercise. The rapid peaks in TNF- $\alpha$ and IL-10 are supported by data published for Wingate SIT [19] and are more akin to the release pattern seen during sepsis $[1,7,11]$. It is unclear, however, whether the cytokine release pattern represents a pro-inflammatory environment or merely relates to increased substrate mobilization. Nonetheless, the postexercise environment may be an important stimulus for long-term positive adaption to high-intensity sprint and interval training regimens.

\section{Competing Interests}

The authors declare that they have no competing interests.

\section{Authors' Contributions}

$\mathrm{CH}$ was involved in all aspects of this research, including the conception, design, data collection and analysis, as well as writing. RS was involved in the design and data analysis editing of this manuscript. Both authors read and approved the final manuscript.

\section{Acknowledgements}

We wish to thank David Morries for his dedication to the project. This study could not have been completed without the support of Virginia Commonwealth University's Center for Clinical and Translational research grant \#UL1TR000058, National Center for Advancing Translational Sciences, as well as the technical and nursing support by the VCU Clinical Research Service Unit. In addition, this study received support from the VCU Dept. of Kinesiology and Health Sciences, SRM USA, and R\&D, Inc, as well as crowd funding support through Experiment.com.

\section{Author details}

'Department of Health and Human Performance, Ferrum College, Ferrum, VA 24088, USA. ${ }^{2}$ Department of Biostatistics, Virginia Commonwealth University, Richmond, VA 23298, USA.

Received: 4 September 2015 Accepted: 22 February 2016

Published online: 01 March 2016

References

1. Armstrong $L$, Jordan N, Millar A. Interleukin 10 (IL-10) regulation of tumor necrosis factor alpha (TNF-alpha) from human alveolar macrophages and peripheral blood monocytes. Thorax. 1996;51(2):143-9. 
2. Babraj JA, Vollaard NB, Keast C, Guppy FM, Cottrell G, Timmons JA. Extremely short duration high intensity interval training substantially improves insulin action in young healthy males. BMC Endocr Disord. 2009:9:1-8.

3. Brestoff JR, Clippinger B, Spinella T, von Duvillard SP, Nindl BC, Arciero PJ. An acute bout of endurance exercise but not sprint interval exercise enhances insulin sensitivity. Appl Physiol Nutr Metab. 2009;34:25-32.

4. Burgomaster KA, Howarth KR, Phillips SM, et al. Similar metabolic adaptations during exercise after low volume sprint interval and traditional endurance training in humans. J Physiol. 2008;586(1):151-60.

5. Coffey VG, Hawley JA. The molecular basis for training adaptation. Sports Med. 2007;37:737-63.

6. Dill DB, Costill DL. Calculation of percentage changes in volumes of blood plasma, and red cells in dehydration. J Appl Physiol. 1974;37:247-8.

7. Dhingra S, Sharma AK, Arora RC, Slezak J, Singal PK. IL-10 attenuates TNFalpha-induced NF kappaB pathway activation and cardiomyocyte apoptosis. Cardiovasc Res. 2009;82(1):59-66

8. Dudley GA, Abraham WM, Terjung RL. Influence of exercise intensity and duration on biochemical adaptations in skeletal muscle. J Appl Physiol. 1982;53(4):844-50.

9. Earnest CP. Exercise interval training: an improved stimulus for improving the physiology of pre-diabetes. Med Hypotheses. 2008;71(5):752-61.

10. Febbraio MA, Pedersen BK. Muscle-derived interleukin-6: mechanisms for activation and possible biological roles. FASEB J. 2002;16:1335-47.

11. Fischer CP. Interleukin-6 in acute exercise and training: what is the biological relevance? Exerc Immunol Rev. 2006;12:6-33.

12. Foster C, Hector LL, MacDonald KS. Measurement of anaerobic power and capacity. In: Maud PJ, Foster C, editors. Physiological assessment of human fitness. Champaign: Human Kinetics; 1995.

13. Gibala M. Use of high intensity training in metabolic syndrome patients. Denver: ACSM Annual Meeting; 2011. p. 43-5.

14. Gibala MJ, Little JP, van Essen M, et al. Short-term sprint interval versus traditional endurance training: similar initial adaptations in human skeletal muscle and exercise performance. J Physiol. 2006;575(Pt 3):901-11.

15. Gray AB, Telford RD, Weidemann MJ. Endocrine response to intense interval training. Eur J Appl Physiol. 1993;66:366-71.

16. Häkkinen $\mathrm{K}$, Pakarinen A. Acute hormonal responses to two different fatiguing heavy-resistance protocols in male athletes. J Appl Physiol. 1993;74(2):882-7.

17. Hashimoto T, Hussien R, Oommen S, Gohil K, Brooks GA. Lactate sensitive transcription factor network in L6 cells: activation of MCT1 and mitochondrial biogenesis. FASEB J. 2007;21(10):2602-12.

18. Hawley JA, Gibala MJ. Exercise intensity and insulin sensitivity: how low can you go? Diabetologia. 2009;52(9):1709-13.

19. Lira FS, Panissa VLG, Julio F, Franchini E. Differences in metabolic and inflammatory responses in lower and upper body high-intensity intermittent exercise. Euro J Appl Physiol. 2015;115:1467-74.

20. Lira VA, Benton CR, Yan Z, Bonen A. PGC-1alpha regulation by exercise training and its influences on muscle function and insulin sensitivity. Am J Physiol Endocrinol Metab. 2010;299(2):E145-61.

21. Lira FS, Rosa JC, Yamashita AS, Koyama CH, Batista ML, Seelaender M Endurance training induces depot-specific changes in IL-10/TNF-alpha ratio in rat adipose tissue. Cytokine. 2009;45(2):80-5.

22. Meckel Y, Eliakim A, Seraev $M$, et al. The effect of a brief sprint interval exercise on growth factors and inflammatory mediators. J Strength Cond Res. 2009;23(1):225-30.

23. Meckel $Y$, Nemet D, Bar-Sela S, et al. Hormonal and inflammatory responses to different types of sprint interval training. J Strength Cond Res. 2011;25(8):2161-9.

24. Nemet D, Meckel Y, Bar-Sela S, Zaldivar F, Cooper DM, Eliakim A. Effect of local cold-pack application on systemic anabolic and inflammatory response to sprint-interval training: a prospective comparative trial. Eur J Appl Physiol. 2009;107:411-7.

25. Nielsen HB, Secher NH, Christensen NJ, Pedersen B. Lymphocytes and NK cell activity during repeated bouts of maximal exercise. Am J Physiol. 1996:40:222-R227.

26. Pedersen BK. Muscles and their myokines. J Exp Biol. 2011;214:337-46.

27. Pedersen BK, Steensberg A, Schjerling P. Muscle-derived interleukin-6: possible biological effects. J Physiol. 2001;536(2):329-37.

28. Petersen AMW, Pedersen BK. The role of IL-6 in mediating the antiinflammatory effects of exercise. J Physiol Pharmocol. 2006;57(S10):43-51.
29. Place $N$, Ivarsson $N$, Venckunas $T$, et al. Ryanodine receptor fragmentation and sarcoplasmic reticulum $\mathrm{Ca} 2+$ leak after one session of high-intensity interval exercise. Proc Natl Acad Sci U S A. 2015;112(50):15492-7.

30. Richards JC, Johnson TK, Kuzma JN, Lonac MC, Schweder MM, Voyles WF, et al. Short-term sprint interval training increases insulin sensitivity in healthy adults but does not affect the thermogenic response to B-adrenergic stimulation. J Physiol. 2010;588(15):2961-72

31. Staczkowski M, Kowalski I, Nikolajuk A, Krukowska A, Gorska M. Plasma interleukin-10 concentration is positively related to insulin sensitivity in young healthy individuals. Diabetes Care. 2005;28(8):2036-7.

32. Steensberg A, Fischer CP, Keller C, Møller K, Pedersen BK. IL-6 enhances plasma IL-1ra, IL-10, and cortisol in humans. Am J Physiol Endocrinol Metab. 2003:285:E433-7.

33. Stepto NK, Hawley JA, Dennis SC, Hopkins WG. Effects of different intervaltraining programs on cycling time-trial performance. Med Sci Sports Exerc. 1999:31(5):736-41.

34. Tabata I, Irisawa K, Kouzaki M, Nishimura K, Ogita F, Miyachi M. Metabolic profile of high intensity intermittent exercises. Med Sci Sports Exerc. 1997;29(3):390-5.

35. Tabata I, Nishimura K, Kouzaki M, Hirai Y, Ogita F, Miyachi M, et al. Effects of moderate-intensity endurance and high-intensity intermittent training on anaerobic capacity and VO2max. Med Sci Sports Exerc. 1996:28(10):1327-30.

36. Thyfault JP. Setting the stage: possible mechanisms by which acute contraction restores insulin sensitivity in muscle. Am J Physiol Regul Integr Comp Physiol. 2008;294:R1103-10.

37. Trilk $J$, Singhal A, Bigelman KA, et al. Effect of sprint interval training on circulatory function during exercise in sedentary, overweight/obese women. Eur J Appl Physiol. 2011;111:1591-1597.

38. Whyte LJ, Ferguson C, Wilson J, et al. Effects of single bout of very highintensity exercise on metabolic biomarkers in overweight/obese sedentary men. Metabolism. 2013;62(2):212-9.

39. Whyte $L J$, Gill JMR, Cathcart AJ. Effect of 2 weeks of sprint interval training on health-related outcomes in sedentary overweight/obese men. Metabolism. 2010;59:1421-8.

\section{Submit your manuscript to a SpringerOpen ${ }^{\circ}$ journal and benefit from:}

- Convenient online submission

- Rigorous peer review

- Immediate publication on acceptance

- Open access: articles freely available online

- High visibility within the field

- Retaining the copyright to your article

Submit your next manuscript at $\boldsymbol{s p r i n g e r o p e n . c o m ~}$ 